\title{
An evaluation of the Coulter S counter
}

A. A. SHARP AND B. C. D. BALLARD

From the Department of Haematology, Radcliffe Infirmary, Oxford

Basic Information

$\cos \mathrm{T}$

$£ 7,000$ from Coulter Electronics Limited, Dunstable, Beds., now $£ 10,000$.

BASIC FACILITIES AND OPTIONAL EXTRAS The complete machine was provided within this cost, including diluter, analyzer, power supply, and printout. Comprehensive instructions and a service manual were provided. These are easy to read and to understand after taking part in the introductory course provided by the manufacturer. The machine can accept one blood sample at a time and subsequent samples at less than 30-second intervals. Information is provided on haemoglobin, red cell count, white cell count, and mean corpuscular volume; the haematocrit, mean corpuscular haemoglobin, and mean corpuscular haemoglobin concentration are deduced from the measured parameters. The results of the analysis are printed directly into labelled spaces on the original request card. All components, glassware and electronic, and circuit cards are easily removable, simple to test, and, if necessary, exchange. There is an indicator light system that monitors all functions of the machine.

PRINCIPLE OF CALCULATION IN THE AUTOMATIC EQUIPMENT

The white and red blood cells are counted by the usual Coulter principle except that the counts which occur during a four-second interval under standard vacuum conditions are registered and not counts in a predetermined volume of diluted blood. These counts are made in triplicate for each parameter and the average result is recorded.

${ }^{1}$ This report has been prepared at the invitation of the Laboratory Equipment and Methods Advisory Group (Lemag) to the Department of Health and Social Security.

The evaluation has been made in accordance with the testing schedule set out in the Appendix.

Received for publication 6 March 1970.
The MCV is calculated from the arithmeticus mean of the height of pulses generated during two of the red cell counts. The haemoglobin is measured by an optical density method as cyanmethaemoglobin. The haematocrit is deduced from the red cell count and MCV, the $\vec{s}$ $\mathrm{MCH}$ from haemoglobin and red cell count and the MCHC from haemoglobin and haematocrit.

All of these parameters are measured and stored by the machine as voltages, these being compare 8 by the machine with voltages generated by as standard blood. The results are expressed in proportion to the original calibration aftero analogue to digital conversion.

\section{RATE OF ANALYSIS}

The claimed performance is one count everyo 20 seconds, the throughput time for a specimen being $\mathbf{4 0}$ seconds. This rate of analysis is possible but it is difficult to maintain over long periods

\section{STANDARDS PROVIDED}

A whole blood standard, marketed under the name of $4 C$, is available at a cost of approxi $\frac{}{8}$ mately $£ 1$ for each determination. This standardE. has not been used.

MULTICHANNELS

While this is not strictly a multichannel machine? because of its sequential analysis system, certaife faults may only affect one parameter and cane 'be lived with' until a replacement part is ob tained.

\section{CAPILLARY BLOOD}

The machine is designed to measure the seven parameters on prediluted samples of capillars blood as an alternative to venous samples. 
$6 \mathrm{ft} \times 6 \mathrm{ft}$ on a bench space of $6 \mathrm{ft} \times 2 \mathrm{ft} 6$ in. The pump unit fits under the bench; no shelves are required. Electricity, 240 v 13 amp circuit, is all that is required. Gas and water are not required. Drainage is not essential but it would, of course, be satisfactory to have the waste outflowing into a drain. The diluent is supplied in 5 gallon collapsible plastic containers, and it is convenient to discharge the waste into these containers to allow flexibility in the positioning of the equipment.

STAFF AND TRAINING

The machine requires staff to be specially trained for standardization, maintenance, and simple repairs; a satisfactory training programme lasting four days is provided by the manufacturer. Only one hour's training is required to operate the machine for routine use.

\section{ARRANGEMENTS FOR REPAIRS}

Service engineers have, up to the moment, been effective when they have come, and have improved as they have gained experience of the machines in use. There has been some delay in obtaining their services but this has been provided in every instance within 24 hours. The service maintenance contract is still an unknown entity, the machine being under guarantee for 12 months. No charges for service have been raised to date.

\section{Samples}

The machine will provide data on $(a)$ venous blood $(0.7 \mathrm{mg}$ potassium EDTA $/ \mathrm{ml})$ and $(b)$ capillary blood, which is stable for at least two hours at a dilution of $1 / 224$ in Isoton (see Reagents below).

\section{MACHINE BATCH}

This machine will only accept one sample at a time; the interval between specimens is not less than 20 seconds.

\section{REJECTION OF UNSUITABLE SAMPLES}

Both on the white and red cell counts, the machine will reject an imperfect count; this is indicated by a red warning light in relation to one, two, or all three of the apertures for the red or white cell count. The machine will produce a result if one count of three is rejected; this is usually the result of a blocked aperture. Rejection by the machine is expressed by the printout of nonsense results. This is immediately evident to the operator and may be due to bubbles in the counting chamber, a large blood clot, or a very abnormal blood, eg, a chronic lymph- atic leukaemia with a white cell count greaten than $50,000 / \mathrm{c} \mathrm{mm}$. This result will be recordec as 99,900 ; a rejected count is recorded as 000 .

LIMITATIONS OF VOLUME OF SAMPLE At least $1.2 \mathrm{ml}$ of blood is required for each count; it is advisable to have at least twice this volume for each sample to allow for duplication of unusual results. Thus, a $5 \mathrm{ml}$ sample of blooc is required to obtain a complete profile.

\section{Reagents}

Isoton buffered saline/20 litres

Lysing agent for haemoglobin/ $500 \mathrm{ml}$

Isoterg detergent for cleaning machine $/ 100 \mathrm{ml}$

Printout cards per 1,000 No reagents have been manufactured in the laboratory.

REAGENTS USED PER SAMPLE

Forty $\mathrm{ml}$ Isoton, $1 \mathrm{ml}$ lysing agent, and one printout card. This does not allow for reagents used during cleansing and standardization procedures (see cost below).

\section{COST PER SAMPLE}

The cost of reagents for one month in this laboratory (July 1969) for 5,598 routine testso in 25 working days is $10.8 \mathrm{~d}$ per test. This can be reduced by printing one's own cards and by preparing diluents locally.

\section{COMPOSITION OF TUBING}

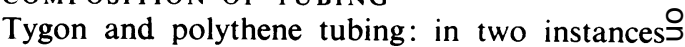
this has worn and broken at pinch valves and caused faults in the machine (see later). Wear resistance of tubing has been satisfactory after $\tilde{O}^{N}$ 11 months' regular use.

\section{Instrumentation}

RANGE OF CHANNELS

The machine will not record WBCs greater than $50,000 / \mathrm{c} \mathrm{mm}$. A higher WBC will affect both $\stackrel{?}{\odot}$ $\mathrm{Hb}$ (change in OD of $1: 250$ dilution) and MCV尺 (also Hct by calculation). (See note on rejection? of unsuitable samples above.)

\section{COLORIMETER}

Haemoglobin is measured as cyanmethaemo- 
globin at a dilution of $1: 250$. A blank or zero $\mathrm{Hb}$ is measured during the rinsing cycle of the machine between each $\mathrm{Hb}$ measured. There is no significant carryover. This machine has proved to be a very accurate haemoglobinimeter; since 1 volt generated represents $1 \mathrm{~g} \mathrm{Hb}$, it is very easy to calibrate.

\section{CELL COUNTERS}

The apertures $(100 \mu)$ tend to become coated with protein, particularly on the WBC side of the machine where blood dilution is $1: 250$. Since this machine registers counts for a fixed period of time, the size of aperture has a very marked effect on the number of particles which may be counted. The apertures are readily cleaned with Isoterg.

\section{PRESENTATION OF RESULTS}

The results are printed in triplicate onto the original request card. These cards have seven parameters tabulated with normal ranges quoted and a space for results.

Provision is made for results to be fed onto punched tape or into a computer. A suitable interface is required for these purposes.

\section{CALIBRATION PROCEDURE}

This is detailed in the manufacturer's handbook.

NEED FOR RECALIBRATION: TIMES PER

DAY OR PER WEEK

The machine may not need recalibration for periods longer than one week. It may, on the other hand, need to be recalibrated daily, but

\begin{tabular}{|c|c|c|c|c|c|c|c|}
\hline Test & $W B C$ & $R B C$ & $H b$ & $\begin{array}{l}\text { Haemato- } \\
\text { crit }\end{array}$ & $M C V$ & $M C H$ & $M C H C$ \\
\hline $\begin{array}{r}30 \\
31 \\
32 \\
33 \\
34 \\
35 \\
140 \\
141 \\
142 \\
143 \\
144 \\
145 \\
310 \\
311 \\
312 \\
313 \\
314 \\
315 \\
316 \\
317 \\
318\end{array}$ & $\begin{array}{l}2 \cdot 7 \\
2 \cdot 6 \\
2 \cdot 7 \\
2 \cdot 7 \\
2 \cdot 7 \\
2 \cdot 6 \\
2 \cdot 6 \\
2 \cdot 7 \\
2 \cdot 6 \\
2 \cdot 6 \\
2 \cdot 7 \\
2 \cdot 7 \\
2 \cdot 6 \\
2 \cdot 6 \\
2 \cdot 6 \\
2 \cdot 5 \\
2 \cdot 6 \\
2 \cdot 6 \\
2 \cdot 5 \\
2 \cdot 5 \\
2 \cdot 5\end{array}$ & $\begin{array}{l}3.54 \\
3.54 \\
3.57 \\
3.61 \\
3.55 \\
3.55 \\
3.58 \\
3.56 \\
3.54 \\
3.57 \\
3.54 \\
3.55 \\
3.61 \\
3.56 \\
3.62 \\
3.59 \\
3.57 \\
3.58 \\
3.63 \\
3.49 \\
3.61\end{array}$ & $\begin{array}{l}10.5 \\
10.6 \\
10.6 \\
10.5 \\
10.5 \\
10.4 \\
10.5 \\
10.4 \\
10.5 \\
10.5 \\
10.5 \\
10.4 \\
10.5 \\
10.4 \\
10.4 \\
10.6 \\
10.6 \\
10.5 \\
10.6 \\
10.4 \\
10.5\end{array}$ & $\begin{array}{l}31 \cdot 7 \\
31 \cdot 9 \\
32 \cdot 5 \\
32 \cdot 6 \\
32 \cdot 3 \\
32 \cdot 3 \\
32 \cdot 5 \\
32 \cdot 3 \\
32 \cdot 2 \\
32 \cdot 4 \\
32 \cdot 1 \\
32 \cdot 5 \\
33 \cdot 0 \\
32 \cdot 4 \\
33 \cdot 4 \\
32 \cdot 9 \\
32 \cdot 6 \\
32 \cdot 9 \\
33 \cdot 3 \\
32 \cdot 1 \\
32 \cdot 6\end{array}$ & $\begin{array}{l}90 \\
90 \\
91 \\
91 \\
91 \\
91 \\
91 \\
91 \\
91 \\
91 \\
91 \\
92 \\
91 \\
92 \\
92 \\
92 \\
91 \\
92 \\
92 \\
92 \\
91\end{array}$ & $\begin{array}{l}29 \cdot 7 \\
29 \cdot 9 \\
29 \cdot 7 \\
29 \cdot 1 \\
29 \cdot 5 \\
29 \cdot 4 \\
29 \cdot 4 \\
29 \cdot 3 \\
29 \cdot 6 \\
29 \cdot 4 \\
29 \cdot 6 \\
29 \cdot 2 \\
29 \cdot 2 \\
29 \cdot 3 \\
28 \cdot 8 \\
29 \cdot 5 \\
29.6 \\
29 \cdot 3 \\
29.1 \\
29 \cdot 8 \\
29 \cdot 1\end{array}$ & $\begin{array}{l}33 \cdot 2 \\
33 \cdot 1 \\
32 \cdot 6 \\
32 \cdot 2 \\
32 \cdot 4 \\
32 \cdot 4 \\
32 \cdot 3 \\
32 \cdot 2 \\
32 \cdot 5 \\
32 \cdot 4 \\
32 \cdot 5 \\
31 \cdot 8 \\
31 \cdot 9 \\
32 \cdot 1 \\
31 \cdot 3 \\
32 \cdot 2 \\
32 \cdot 4 \\
31 \cdot 7 \\
31 \cdot 7 \\
32 \cdot 3 \\
32 \cdot 1\end{array}$ \\
\hline
\end{tabular}

Table I Within-day precision ${ }^{1}$

'Standard blood was used as control during working day. Test numbers show place of standard blood amongst routine specimens. seldom requires to be recalibrated during the working day.

\section{BLANK DETERMINATIONS}

These can be determined by running Isoton:instead of blood through the machine. Occasion ally, the machine may appear to need recalibra tion when, in fact, a high blank due to dirt in the Isoton is the fault.

\section{Evaluation of Performance}

\section{ACCURACY}

This machine is only as good as its operatori It is designed to reproduce exact results on $a_{p}^{\omega}$ given standardized sample of blood and there after all samples are compared with this standard.N Unless the precise answer for a standard blood sample is available from other sources, results. will only be as accurate as those obtained by conventional techniques. When accurately calibrated, this machine will reproduce data for a period of time, which may be longer thand one week. It has been impossible to compare this machine with others which perform similae estimations because only this equipment was available for test. In general terms, the $\mathrm{Hb}$ and white cell count are every bit as good as bxo any other routine manual method and the RBC count is certainly superior. The accuracy o $\overrightarrow{\vec{B}}$ the haematocrit is less easy to define because it is a deduced result. There is some value in this measurement, since if the machine confirms the microhaematocrit on a standard blood, the machine RBC count and MCV are probablys accurate. Absolute indices have been found to be more informative than those based op conventional manual RBC counts.

A national whole blood primary standardo issued at weekly intervals, is urgently required in order that accuracy can be more readils. achieved and maintained.

\section{PRECISION (DAILY AND DAY-TO-DAY} REPRODUCIBILITY)

Precision has been determined in three wayso (1) By preparing a bulk blood in Alsever solution and testing this sample several times per day an ${ }^{\circ}$ between days (Table I and Fig. 1); (2) by dailyo carryover of 12 samples from day 1 to day 2 and so on; and (3) by calculating a daily mean fon the measured parameters of the machine, $i_{\mathscr{Q}}^{\mathbb{D}}$ $\mathrm{Hb}$, red cell count, white cell count, and $\mathrm{MCV}$ (Fig. 2) and daily mode for the MCV, MCH, and MCHC.

Reproducibility over one day has been ex tremely precise for all parameters (Table I) between-day precision has also proved satisfactory 
110

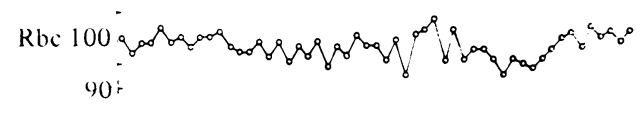

$110+$

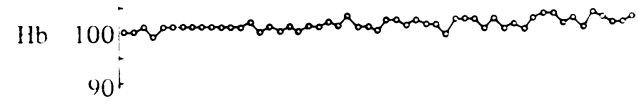

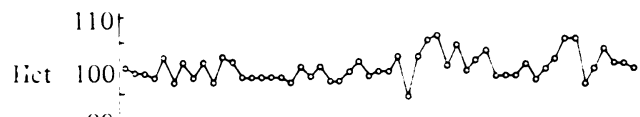

$90 r$

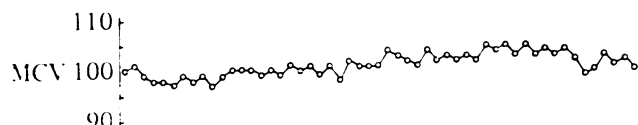

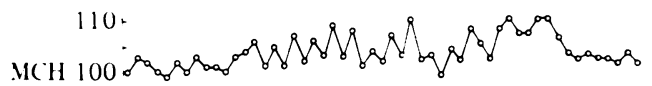
90.

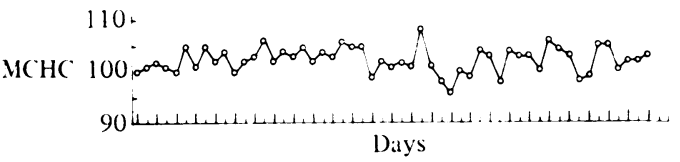

Fig. 1 Daily results on standard blood in Alsever's solution expressed as percentage difference, day 1 results being taken as $100 \%$.

(Fig. 1). (These results are expressed as a percentage of the first result obtained and they also demonstrate the stability of blood in Alsever solution.)

\begin{tabular}{|c|c|c|c|c|c|c|c|}
\hline Estimation & $A_{1}$ & $A_{2}$ & $A_{3}$ & $B_{1}$ & $B_{2}$ & $B_{3}$ & $\kappa \frac{B_{1}-B_{3}}{A_{3}-B_{3}}$ \\
\hline WBC & $\begin{array}{l}5 \cdot 7 \\
8 \cdot 0 \\
8 \cdot 2 \\
6 \cdot 1 \\
6 \cdot 1\end{array}$ & $\begin{array}{l}5 \cdot 8 \\
8 \cdot 3 \\
8 \cdot 6 \\
6 \cdot 1 \\
6 \cdot 1\end{array}$ & $\begin{array}{l}6 \cdot 0 \\
8 \cdot 4 \\
8 \cdot 5 \\
6 \cdot 1 \\
6 \cdot 1\end{array}$ & $\begin{array}{l}1.6 \\
2.0 \\
0.5 \\
0.4 \\
0.5\end{array}$ & $\begin{array}{l}1 \cdot 5 \\
1 \cdot 6 \\
0 \cdot 3 \\
0 \cdot 3 \\
0 \cdot 3\end{array}$ & $\begin{array}{l}1 \cdot 5 \\
1 \cdot 5 \\
0 \cdot 3 \\
0 \cdot 3 \\
0 \cdot 3\end{array}$ & $\begin{array}{l}0.0222 \\
0.0725 \\
0.0244 \\
0.0172 \\
0.0345\end{array}$ \\
\hline $\mathbf{R B C}$ & $\begin{array}{l}5 \cdot 19 \\
8 \cdot 72 \\
8 \cdot 43 \\
4 \cdot 98 \\
5 \cdot 13\end{array}$ & $\begin{array}{l}5.24 \\
8.93 \\
8.60 \\
5.00 \\
5.17\end{array}$ & $\begin{array}{l}5.21 \\
8.94 \\
8.62 \\
5.09 \\
5.17\end{array}$ & $\begin{array}{l}0.97 \\
1.21 \\
0.27 \\
0.28 \\
0.28\end{array}$ & $\begin{array}{l}0 \cdot 83 \\
0 \cdot 86 \\
006 \\
0 \cdot 17 \\
0 \cdot 17\end{array}$ & $\begin{array}{l}0.80 \\
0.82 \\
0.03 \\
0 \cdot 18 \\
0 \cdot 16\end{array}$ & $\begin{array}{l}0.0385 \\
0.0480 \\
0.0279 \\
0.0204 \\
0.0240\end{array}$ \\
\hline $\mathrm{Hb}$ & $\begin{array}{l}16.2 \\
27.7 \\
276 \\
13 \cdot 7 \\
14.5\end{array}$ & $\begin{array}{l}16 \cdot 3 \\
27 \cdot 5 \\
27.5 \\
13 \cdot 7 \\
14 \cdot 7\end{array}$ & $\begin{array}{l}16 \cdot 2 \\
27.8 \\
278 \\
13.7 \\
14.7\end{array}$ & $\begin{array}{r}03.0 \\
3.7 \\
05 \\
0.0 \\
0.1\end{array}$ & $\begin{array}{r}02 \cdot 7 \\
2 \cdot 8 \\
0 \cdot 2 \\
0 \cdot 0 \\
0 \cdot 0\end{array}$ & $\begin{array}{r}02.6 \\
2.8 \\
0.0 \\
0.0 \\
0.0\end{array}$ & $\begin{array}{l}0.0294 \\
00360 \\
0.0180 \\
0.0000 \\
0.0068\end{array}$ \\
\hline Haematocrit & $\begin{array}{l}47 \cdot 9 \\
82 \cdot 2 \\
82 \cdot 5 \\
43 \cdot 5 \\
45 \cdot 9\end{array}$ & $\begin{array}{l}48 \cdot 6 \\
83 \cdot 6 \\
84 \cdot 3 \\
43 \cdot 7 \\
46 \cdot 8\end{array}$ & $\begin{array}{l}48 \cdot 8 \\
84 \cdot 3 \\
83 \cdot 8 \\
44 \cdot 4 \\
47 \cdot 0\end{array}$ & $\begin{array}{r}8.7 \\
11.0 \\
02.1 \\
2.2 \\
2.1\end{array}$ & $\begin{array}{l}7 \cdot 3 \\
7 \cdot 8 \\
0 \cdot 4 \\
1 \cdot 2 \\
1.2\end{array}$ & $\begin{array}{l}7.1 \\
7.4 \\
0.1 \\
1.4 \\
1.2\end{array}$ & $\begin{array}{l}0.0384 \\
0.0468 \\
0.0239 \\
0.0186 \\
0.0197\end{array}$ \\
\hline
\end{tabular}

Table II Carryover ${ }^{1}$

${ }^{1} A$ and $B$ designate different bloods tested in groups of three consecutive estimations.

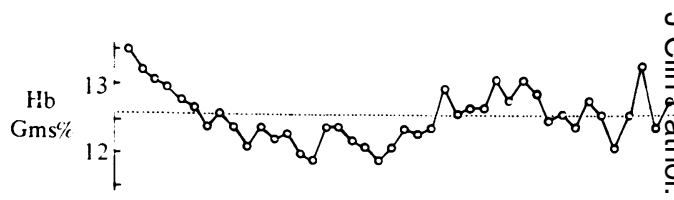

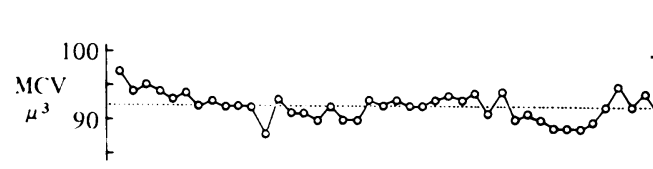

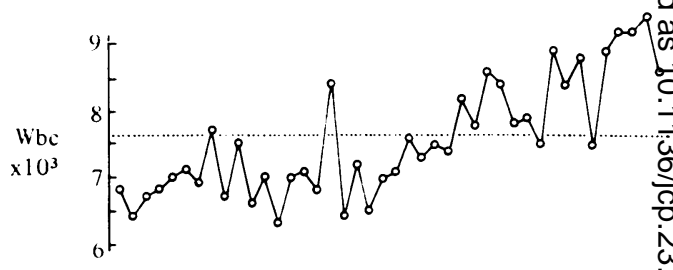

$\mathrm{Rbc}$

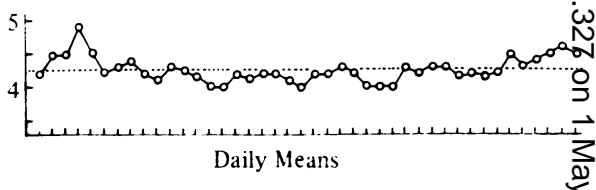

Fig. 2 Daily means of 100 unselected routine laboratory investigations.

\section{COMPARISON WITH CONVENTIONAL METHODS}

This was performed daily over the first month to determine whether samples were being measured correctly by the machine in relation to low, normal, and high values. These checks were satisfactory; the results were essentiall the same as those illustrated by Barnard, Carter. Crossland-Taylor, and Stewart (1969).

\section{CARR YOVER}

The results of carryover experiments are shown in Table II. For all parameters carryove? is minimal and acceptable.

\section{LINEARITY}

The results obtained are satisfactory in relatio to linearity (Fig. 3).

White blood cell count was linear betwee 700 and 40,000 cells/c mm. White cell counts below 700/c mm could not be measured a curately, red blood cell counts between 200,00\% and 7 million cells $/ \mathrm{c} \mathrm{mm}$, and $\mathrm{Hb}$ between $0.2 \mathrm{~g} \%$ and $20 \mathrm{~g} \%$.

DRIFT

There has been no evidence of within-day drif (Table I), as during any working day the maching is not switched off and all samples are considere as one batch. There has been evidence of betweeff day drift which emphasizes the need for continuat 

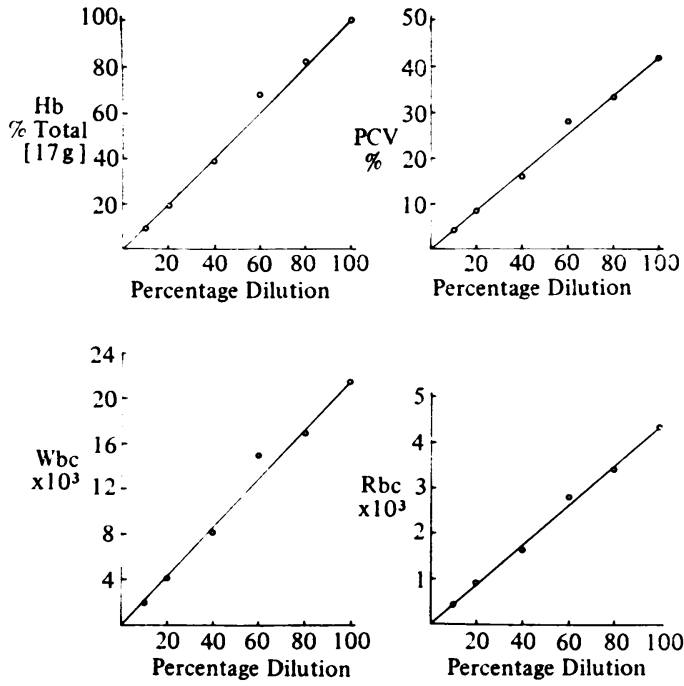

Fig. 3 Linearity: results obtained by serial manual dilution of a given blood.

supervision and recalibration if necessary, ie, any need for recalibration must indicate a drift (Fig. 2).

\section{CAPILLARY BLOOD}

The results obtained on the prediluted samples of capillary blood have been satisfactory within the limitations imposed by sampling capillary blood and manual dilution.

\section{Accuracy or 'Truth' in Abnormal Bloods}

Over a period of 11 months, there has been ample opportunity to determine the usefulness of this machine for performing analyses of abnormal bloods. This experience has revealed the great value of having indices available on every count and has emphasized on several occasions that individual subjective assessment of red cell morphology in blood films, even by those with several years' experience, can be fallacious.

The following specific observations have been made:

\section{HYPOCHROMIA}

The machine is extremely sensitive to hypochromia as expressed by the $\mathrm{MCH}$ (mean corpuscular haemoglobin) and to microcytosis as measured by the MCV (levels as low as $16 \mu \mu \mathrm{g}$ and less than $60 \mu^{3}$ having been recorded). Mild hypochromia and microcytosis, as measured by these indices, often cannot be reliably detected by light microscopy. Further, a definite hypo- chromic microcytic red cell picture can exist ${ }^{\complement}$ in non-polycythaemic and non-thalassaemic patients with little or no anaemia.

\section{MACROCYTOSIS}

Similarly, the equipment is very sensitive tos macrocytosis. In several instances an MCVO greater than $105 \mu^{3}$ has been encountered witho haemoglobin levels in the low normal range $\frac{}{f}$ (13-14 $\mathrm{g} \%$ ). Whilst examination of blood films has usually confirmed these indices, then macrocytosis has not been obvious and could easily have been missed by cursory examination: Justification for these comments has been $\vec{\omega}$ obtained in the majority of instances by theos presence of megaloblasts in the marrow or the presence of jaundice or liver damage.

\section{THALASSAEMIA}

The machine detects the thalassaemia trait ing the non-anaemic heterozygote by revealing $a-$ striking hypochromic $(\mathrm{MCH}<20 \mu \mathrm{g})$ micro-3 cytic anaemia with a high red cell count ( $><$ $5,000,000 / \mathrm{cmm})$ and a normal or near normate haemoglobin value. Confirmation of theses findings is, of course, usually evident in the blood films when the observer is pre-conditioned bys the count.

\section{SPHEROCYTOSIS}

The presence of definite spherocytes is suggested by a high MCHC $36 \%$ (normal mode $33 \%$ ).

\section{DISTORTED RED CELLS}

The indices do not give any definite patterniwith acanthocytes or fragmented red cells. These changes can only be detected in blood films.

\section{MIXED POPULATIONS}

The double population of red cells classicallyo found in treated iron deficiency or in the double deficiency states, eg, steatorrhoea, cannot be detected by use of these indices. Each case gives results dependent on the dominant red cel population. It is, therefore, possible to miss aृ macrocytic element associated with a hypoo chromic microcytic state unless a film is examined

HIGH WHITE CELL COUNTS

White cell counts up to $40,000 / \mathrm{c} \mathrm{mm}$ do no appear to interfere with the measurement of haemoglobin or MCV. Higher counts may do soIn these instances, accurate white cell counts may have to be obtained by manual methodg and a lysing agent must be used to destroy the white cells before measuring the true haemoglobif level. 


\section{Reliability}

FAULTS

The machine was installed on 10 March 1969.

\section{March}

The $\mathrm{Hb}$ values were too high. Fault traced to sticky pinch valve controlling lysing agent supply. This fault has occurred on three occasions, is easy to recognize, and on the first occasion took about 30 minutes to repair.

\section{March}

Fault in lefthand printer. The machine functions well on one printout, it is then possible to process one specimen every 40 seconds. Faulty printer was replaced during the afternoon of 14 March.

\section{April}

Printout does not function. Fault traced to bad electrical connection - analyzer to power supplyone hour.

\section{April}

Faulty printout. Service engineer called early morning, arrived within three hours. Faulty analogue/digital converter and timer generator cards exchanged. Into use again early afternoon.

\section{April}

Erratic results. Fault traced to leak in vacuum supply (card L2, valve 8); tubing is punctured at a pinch valve. Replaced and fault cured. One and a half hours.

\section{May}

Air leak into lysing agent supply-inaccurate $\mathrm{Hb}$ and WBC. Fault traced to syringe measuring and dispensing lysing agent. One hour.

\section{May}

Sampling valve is leaking; most obvious effect is erratic RBC counts. New valve was supplied within four hours by service engineer.

\section{August}

Leak of air into lefthand RBC aperture tubing, corrected at joint immediately behind aperture assembly. Half an hour.

\section{August}

MCV reading not steady. Fault traced to MCV card. Replaced morning of 15 August by service engineer. One and a half hours to trace fault.

\section{August}

New MCV card. New pneumatic cards: L1, which controls sampling of whole blood and first dilution for $\mathrm{RBC}$ count, and R2, which controls the dispensing and measurement of lysing agent. These were modifications to upgrade the machine.
26 August

Leak in tubing between syringe dispensin Isoton and mixing/dilution chambers. Tubingo replaced after one and a half hours.

\section{5/6 September}

Fault in new card R2 controlling lysing agent $\frac{\overrightarrow{\bar{\phi}}}{+}$ card was modified to work until service enginee called on Monday, 8 September. Replaced witl任 a second new card R2. Two and a half hours.

\section{September}

Printout. Breakdown of drive mechanism.

No further faults have occurred to (17.2.1970).

The machine has been reliable over 11 months It is again emphasized that it has been in use foro routine work virtually from the day it arrivedi It has only been completely out of use for ones half day in this period. If one measured para meter gives false results, it is possible to carry on and salvage correct results in other para-o meters and correct the fault when time permits.

\section{$\cos \mathrm{TS}$}

To the cost of reagents etc must be added the cost of technical staff $(\times 2)$ and amortization of equipment over a period of five years.

\section{STAFF}

The machine requires two technicians full time $\overrightarrow{\vec{P}}$ to operate it. The second technician is largely performing clerical duties and, in fact, one technician can operate the machine satisfactorily and take through a whole day's work, if his or her only function is to work the Coulter S. ? This technician cannot also carry out clerical duties such as transferring data from the printout cards when they are completed onto regulationsize laboratory cards. No staff time is required in preparing reagents.

\section{DAILY MAINTENANCE}

This requires approximately one hour per for the operating technician to prepare machine, to check the calibration, and to clean $\omega$ the machine at night.

\section{CALIBRATION AND MAINTENANCE}

This requires three hours per week.

SKILL

Actual operation minimal. Maintaining accuracy requires the average skill of a senior technician. $\delta$ Maintenance, diagnosis of faults, and calibration require considerable practice on the part of a technician with mechanical aptitude. The manu- 
facturers' training programme provides a good ground for acquiring these skills.

\section{ANXIETY FACTOR}

This is minimal now, but in the initial stages was considerable. A great deal of work, calibration, and recalibration had to be done until it was proved that the machine was providing accurate and precise results. We repeat, there is an urgent need for an accurate and stable primary standard to be made available at weekly intervals.

Initially, all staff have to become accustomed to trusting the results produced by the machine; it has been found that unexpected results are more likely to be correct or due to a bad specimen rather than to machine error.

EVALUATION OF USE

This machine is eminently suitable for use in a large hospital and for screening procedures. It is probably a costly item for hospitals doing less than 200 investigations per day; its use has emphasized the need for centralization. A full workload for this machine would appearc to be about 400 samples per eight-hour shift $\cong$ or working day. This allows for maintenance time and for small faults to be repaired withouto disturbing the whole daily tempo of work. ప Larger numbers of samples, of course, could be taken through, but this would not allow for $\overrightarrow{\vec{s}}$ any breakdowns or need for recalibration duringo the day; continuous working at this load mighto lead to more inaccurate results and more break- $\frac{\bar{c}}{\vec{D}}$ downs.

\section{Generalized Subjective Report}

This machine has stood up to the manufacturers claims. As mentioned before, it is only as goodit as the operator but the general reliability has $\omega$ been remarkable.

The results provided by the machine when compared with blood films and clinical practiceo are satisfactory for the practice of hospital haematology, and have improved the accuracys and scope of diagnosis, especially in the de tection of early or minimal defects.

\section{Appendix}

\section{Proposed testing schedule for evaluation of equipment in haematology laboratories}

\section{A. A. SHARP}

While many of the problems associated with the use of automatic machinery in chemistry are similar to those in haematology, the latter discipline, involved in determining particle or cell numbers of varying size in normal and abnormal states, is presented with a more complex problem.

Any testing schedules should evaluate the provided machinery in a series of well defined steps, and the following is submitted as an outline schedule for testing equipment. Although originally designed for testing automatic blood counters, the suggested format is adaptable for a wide variety of equipment for use in haematology laboratories.

\section{Basic Information}

(a) Basic cost (b) Basic facilities and optional extras

(c) Type of tests that the machine can perform: manufacturers' claim and actual

(d) Principle of each measurement, eg, $\mathrm{Hb}, \frac{\mathrm{O}}{2}$ RBC, WBC, platelets PCV, MCV, MCMC, $\mathrm{MCH}$

(e) Rate of analysis: claimed performance and actual performance

(f) Throughput time/sample

(g) What standards are provided?

(h) Can each channel be modified for discretec analysis at introduction of sample

(i) Can the machine be used to measure pre diluted samples of capillary blood?

$(j)$ What space and services does the machine require-floor area, bench space, shelves, gas, drainage, electricity, water

(k) Does the machine require that staff be specially trained (a) to operate the machineo for routine use, (b) for maintenance

(l) Arrangements or repairs and maintenance $\frac{\overline{0}}{0}$

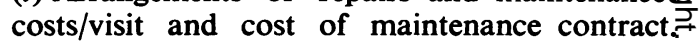




\section{Samples}

(a) What type of sample is required: type of anticoagulant and concentration of anticoagulant (b) Facilities for rejection of unsuitable sample: haemolysed, clotted etc.

(c) Method of presentation: single samples or multiple samples on turntable

(d) Limitations of volume of sample.

\section{Reagents}

(a) What reagents are required: supplied by manufacturer and prepared in laboratory

(b) If prepared in laboratory, details of preparation

(c) Volumes of reagents used/hour or working day

(d) Composition of tubing in the machinewill this stand common reagents?

(e) Life expectancy of tubing or other parts.

\section{Instrumentation}

(a) Colorimeter-details

(b) Cell counters-details

(c) Packed cell volume-details

(d) Output: graphical and printout

(e) Facilities for other forms of display, eg, transfer to punch tape

(f) If graphical display-how are final figures calculated?

( $g$ ) If printout-details of actual figures

(h) Range of each channel

(i) Coordination of channels

(j) Other-specify

\section{Operation Trial}

DEFINITION OF ACCURACY OR TRUTH IN RESULTS IN NORMAL BLOOD

If the various parameters are to be measured against one another, and if subtle variations of results are going to modify clinical impression or therapeutic activity, then the first step in a trial of any machine must be to define if the machine is giving accurate answers to each and every parameter measured. It is obviously unsatisfactory if, say, the haemoglobin and white cell count are correct but the red cell count, packed cell volume and, therefore, all indices are incorrect.

The degree of acceptable error from true values must be defined and it is probably not desirable to accept those errors which we have

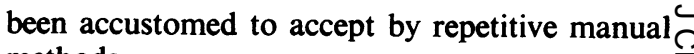
methods.

A suggested acceptable level is as follows: haemoglobin $\pm 1 \%$, red cell count $\pm 2 \%, \stackrel{\circ}{\rightleftharpoons}$ white cell count $\pm 10 \%$, and PCV $\pm 1 \%$. These limits from true values must be the initial optimum and deviation from this must be $\stackrel{\mathcal{O}}{\stackrel{\rho}{\rho}}$ defined.

\section{METHOD}

While certain standards do exist, the whole bloods or particle standards have still to be defined and easily obtainable. Thus there would appear to be no escape from the use of a local $\vec{\omega}$

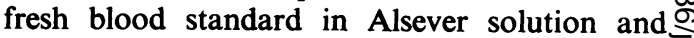
processed each 10-20 samples in order to check용 all measuring systems in the machine during $\underset{\omega}{N}$ the day and for maintenance of accuracy and $\rightarrow$ precision from day to day. Such a standard ${ }_{N}^{\omega}$ would require:

(a) Haemoglobin estimation on $\times 3$ separate 은 manual dilutions by spectrophotometer and/or check with International Standard.

(b) Visual red cell counts on $\times 3$ separate dilutions counting 1,000 cells (photographs of $\vec{\theta}$ counting chambers may have to be used).

(c) Visual white cell counts-as for red cell counts.

(d) Packed cell volume determined $\times 3$ by microhaematocrit level.

ACCURACY AND 'TRUTH' IN ABNORMAL BLOODS

If the machine can be adjusted to demonstrate the truth in normal blood, it must also be able to define the truth in abnormal blood, eg, in hypochromia, macrocytosis, spherocytosis, distorted red cells, mixed populations, and high white cell counts, eg, in leukaemia.

The usefulness of any machine must be measured by its ability to demonstrate ab- 을 normalities and a summary of clinical accuracy should be recorded over a period of time, eg, in relation to films as well as to other investigations and clinical assessment.

\section{Precision (Once Accuracy is Established)}

\section{REPLICATION OF RESULTS}

The ability of the machine to produce on ${ }^{\circ}$ repeated samples of the same blood must be $\stackrel{\mathbb{D}}{\circ}$ determined and the acceptable errors defined as $\mathbb{D}$ above.

CARR Y OVER

Carryover from one sample to another could produce considerable error. Repeated results 
for each parameter must be determined offering bloods giving high and low results alternatively and/or three high alternating with three low levels. Further carryover to saline blank or error after the use of a blank should be measured.

In relation to haematology alternating two abnormal bloods should also be attempted.

The use of radioisotopes may be worth introducing to aid this measurement.

\section{DRIFT}

The relationship of daily or between day must be determined by the introduction of the standard normal blood as described above.

Whether drift as defined by chemists can be accepted by haematologists will have to be determined. Arbitrary corrections for drift may be acceptable for certain biochemical parameters but may give erroneous results if one line drifts out of phase with another, eg, red blood cell count from haemoglobin.

\section{RELIABILITY}

This can only be determined by assessing results, standards, and tests over a prolonged time, eg, six months. Continuous use for 24 hours as suggested by others is hardly a practical proposition.

Intermittent use during a working week would seem to be a more useful test of reliability in actual working conditions.

\section{RUNNING COSTS}

Costs/batch or per 100 tests of (a) reagents, (b) standards, (c) consumables, eg, tubing, paper, charts, etc, $(d)$ repairs and maintenance, and (e) staff time operating, preparing reagents, and in daily maintenance.

SKILL

It is important to define the skills required for actual operation, determining accuracy, maintenance, and preparation of reagents. Include depreciation over five years and deduce overall cost per test.

\section{ANXIETY FACTOR}

Finally, it is important to define machines in terms of their anxiety to the operator, viz, some complicated equipment, although requiring skill and care, will produce consistently reliable results without wasting the operator's time. Other equipment may produce reliable results only after the operator has spent considerable time adjusting or even dismantling and reassembling the machine to clean or repair certain items of equipment; yet, on trial, such a machine might produce acceptable results.
This might be termed an 'anxiety factor' in ${ }^{\complement}$ the working day, but might more accurately $\bar{\equiv}$ be expressed in terms of the average hours/day 0 spent fiddling with the contraption to get it to work. Obviously an average of 0.5 hours would $\underline{\underline{0}}$ be acceptable, but if this were to go above two hours, user fatigue and/or neurosis would be $\stackrel{\vec{\rho}}{\stackrel{9}{?}}$ considerable.

EVALUATION OF USE

Finally, an assessment of an acceptable machine should be made as to suitability for a large hospital, small hospital, or screening procedures.

This schedule has been prepared at the invitation of the Laboratory Equipment and Methods Advisory iv Group to the Department of Health and Social $\omega$ Security. The advice and criticism of Dr Mitchell Lewis, Mr M. Bittulph, of the Department of Health N and Social Security, and Mr Scantlebury, AWRE, Aldermaston, were invaluable during the preparation of this document.

Reference

Barnard, D. F., Carter, A. B., Crossland-Taylor, P. J., and Stewart, J. W. (1969). An Evaluation of the Coulter Model 'S'. In Symposium on Automation and Data Processing in Pathology. J. clin. Path., 22, Suppl. (Coll. Path.) 3, 26-33. 